Voix et Images

voixetimages

\title{
L’opéra-punk du bon barbare
}

\section{Bernard Andrès}

Volume 9, numéro 2, hiver 1984

\section{Roland Giguère}

URI : https://id.erudit.org/iderudit/200448ar

DOI : https://doi.org/10.7202/200448ar

Aller au sommaire du numéro

\section{Éditeur(s)}

Université du Québec à Montréal

\section{ISSN}

0318-9201 (imprimé)

1705-933X (numérique)

Découvrir la revue

Citer cet article

Andrès, B. (1984). L'opéra-punk du bon barbare. Voix et Images, 9(2), 165-166. https://doi.org/10.7202/200448ar d'utilisation que vous pouvez consulter en ligne.

https://apropos.erudit.org/fr/usagers/politique-dutilisation/ 


\title{
L'OPÉRA.PUNK DU BON BARBARE
}

\author{
par Bernard Andrès, Université du Québec à Montréal
}

Nous devrons certainement attendre quelques lustres avant que la figure de l'Indien ne soit correctement assimilée par l'imaginaire québécois, même si elle le travaille sans relâche depuis les relations de voyage, les romans historiques et d'aventure du siècle dernier, jusqu'aux textes de Hémon, Bugnet, Ferron, Beaulieu et, tout récemment, Lalonde. Il faut croire que certains comptes ne sont pas encore réglés avec cet Autre d'ici dont on s'obstine à exhiber les plumes et à vanter le bon naturel, dans une vision décidément figée du bon sauvage. On pourrait pourtant s'attendre à autre chose de la part d'un théâtre "expérimental», moins soumis en principe aux stéréotypes. Voilà quelques années, la Compagnie à Quatre pattes avait proposé une excellente (re)présentation du problème indien au Canada (ou plutôt du problème canadien avec les Amérindiens). À peu près en même temps que la reprise des Grands soleils de Ferron par le Théâtre du Coulonges, l'Hallali de la race rouge ${ }^{1}$ abandonnait le folklore pour tracer le portrait d'une nation éclatée par les colonisations blanches successives. Elle le faisait au travers d'un montage de textes et documents d'époque. La pièce ne manquait ni d'allure ni d'imagination dans la mesure où son aspect documentaire n'écrasait jamais la représentation. Tout était visualisé, le spectateur lui-même intégré dans l'espace de l'Autre par un faisceau de cordes tendues dans la salle (l'arpentage des Territoires de l'ouest), au coeur d'une énorme toile d'araignée aux diagonales du drapeau britannique.

Tout autres sont l'espace et le jeu d'Opus contre nature, 2 de RobertÉmile Audette, présenté en septembre dernier au Conventum. Sous prétexte d'exalter l'image de l'androgynie, l'Opus érige de bric et de broc un genre d'opéra-punk du bon barbare. Plumes écarlates de la prêtresse aux seins nus, lances de bambou, lambeaux de fade nudité, fond de tam-tam, ponts (métalliques!) suspendus en guise de lianes... et cage à macaque. Car dans ce joyeux pot-pourri, les attributs de l'indianité font bon ménage avec ceux de la négritude. Gestuelle, maquillage, bande-son tonitruante, tout est ravalé au rang de la sous-animalité, sur fond de texte vaguement utopiste: «le jour où pastel et anarchie s'uniront dans un même espoir» (!). Cet appel

1. Pendant que plus loin, l'on sonne l'hallali de la race rouge, par la Cie à Quatre pattes, à la Galerie Média, printemps 1977.

2. Opus contre nature, texte et mise-en-scène de Robert-Émile Audette, présenté par l'Eskabel à l'inauguration de sa nouvelle salle du Conventum, 1237 Sanguinet, à Montréal. 
à la révolte des animaux humains débouche en fait sur une revendication hédoniste digne de la belle époque hippie: «Mon frère, bande-toi et n'aie aucune agressivité», ou: «Mon amour pour vous est sans sexe, illimité». Phrases répétées, litanies sentant le procédé, avec à l'occasion, effets pseudo-durassiens: «C'est l'été... Je crois apercevoir des enfants qui jouent». Je m'en voudrais de caricaturer une option après tout défendable, si elle n'était elle-même caricaturée (involontairement) par le spectacle luimême. Le dérèglement des sens a son charme et j'y goûte dans la mesure où précisément il parle à mes sens, suscite mes affects, provoque en moi l'adhésion immédiate, en faisant l'économie du verbe et de l'intellection. Or, rien de plus verbeux que ce froid discours sur l'androgynie, que rejoint rarement l'aspect spectaculaire de la manifestation.

Il y a certainement dans la vision homosexuelle du monde et dans le spectacle de l'homosexualité ou de l'androgynie quelque chose d'assez troublant, une séduction que d'autres spectacles de l'Eskabel avaient admirablement mise en scène (je songe notamment à l'adaptation de Mort à Venise et à l'Hôtel des Glaces). Rien de cela dans cet Opus qui ouvrait pourtant la saison de l'Eskabel dans son nouveau local du Conventum. La pièce d'Audette entreprend confusément de marquer la gradation entre homosexualité et androgynie. L'hermaphrodite exposé en finale est à l'image de toute la représentation: seins postiches et jeu affecté, à l'enseigne de la facticité ambiante du spectacle. Au sortir de ce laborieux Opus, véritable pensum de la rentrée, on ne pouvait qu'espérer une suite plus heureuse à l'Eskabel, en songeant par exemple au texte d'Aquin qui serait monté deux mois plus tard: la Toile d'araignée. 